\title{
ESQUECER BÁRbara Virgínia? UMA CINEASTA precursora entre Portugal e O Brasil
}

\author{
Paula Sequeiros \& Luísa Sequeira
}

\begin{abstract}
RESUMo
Bárbara Virgínia foi uma das primeiras realizadoras de cinema em Portugal e no Festival de Cannes. Iniciando-se artisticamente como declamadora e atriz, dirigiu, muito jovem, uma longa metragem e um documentário em 1946. Imigrou em 1952 para o Brasil para trabalhar em rádio e televisão. Aí se radicou, constituiu família, abandonando a declamação, e faleceu em 2015. Neste artigo recolhemos e analisamos documentação pública e de memória privada, uma entrevista de investigação e conversas com familiares. Recorremos à história e memórias do cinema português para produzir, de um ponto de vista feminista, uma análise sócio-biográfica. Recusando a mitificação, pretendemos contribuir para a desocultação do olhar patriarcal na literatura produzida sobre esta figura. Os estudos de género de Linda Alcoff e Teresa de Lauretis, a sociologia da cultura de Pierre Bourdieu que Bev Skeggs convoca num cruzamento entre classe, género e colonialidade, e ainda investigação histórica e social sobre os contextos dos dois países alimentaram este questionamento e análise. A sócio-biografia apresentada enfoca-se nos papéis artístico e familiar de Bárbara Virgínia, pretendendo alimentar o conhecimento fino sobre barreiras de género e classe em torno das práticas culturais e profissionais na época e ainda discutir o apagamento da memória sobre a realizadora.
\end{abstract}

\section{Palavras-chave}

Cinema; mulheres realizadoras; Estado Novo; Portugal

\begin{abstract}
Bárbara Virgínia was a forerunner film director in Portugal and the Festival de Cannes. Starting artistically as a diseuse and actress, she directed a feature film and a documentary in her youth, in 1946. Bárbara emigrated to Brazil in 1952 to work on radio and television, the country where she settled, formed a family, eventually abandoning the stages, and died in 2015. For this socio-biography, we collected and analysed public and private memory documents, a research interview and conversations with her family. To construct our analysis and strengthen a feminist perspective, we used Portuguese cinema's History and memoirs. We both avoided mythologising and aimed at unveiling the patriarchal gaze which shapes some literature about Bárbara Virgínia. We built our questioning and analysis from Linda Alcoff's and Teresa de Lauretis's gender studies, from the sociology of culture by Pierre Bourdieu who Bev Skeggs borrowed for her intersection of class, gender and coloniality, alongside historical and social research about both countries' context. The paper focuses on the artistic and familiar roles played by the filmmaker, and proposes an interpretation aimed to contribute to a fine knowledge about gender and class barriers to cultural and professional practices at that time, while it also discusses the erasure of memory about Barbara Virginia.
\end{abstract}

KEYWORDS

Cinema; women directors; the New State regime; Portugal 


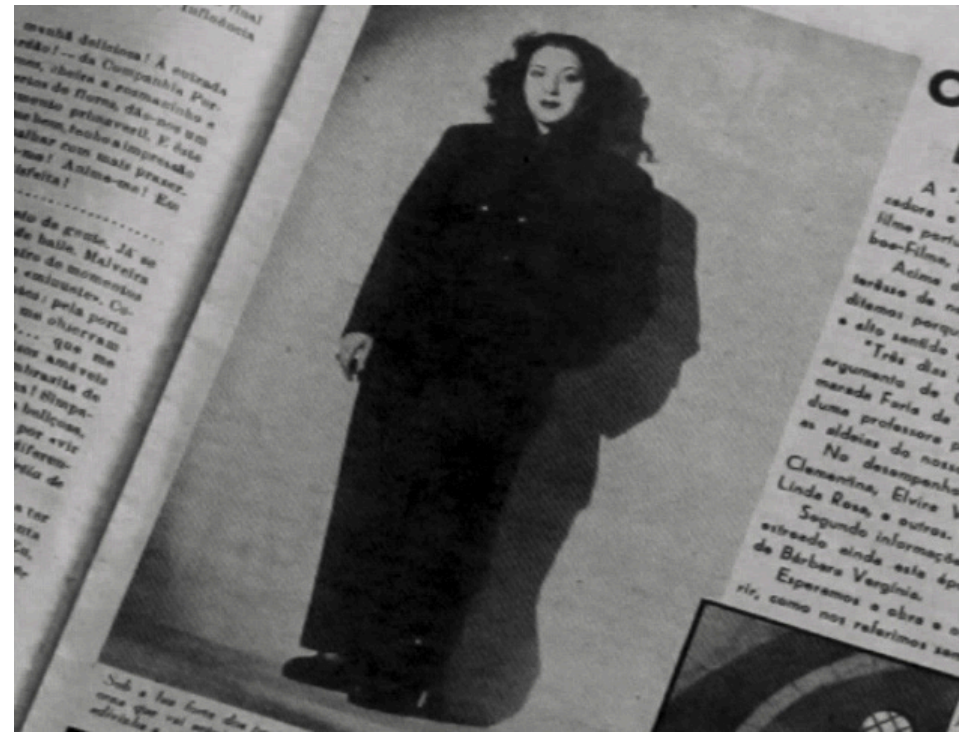

Figura 1: Bárbara Virgínia nos estúdios da Invicta Filmes Independente, inserção no artigo "O Filme da "simpatia""

Fonte: O filme da "simpatia", 1946, p. 5

Encostada a uma parede do estúdio, de fato masculino, uma Bárbara Virgínia de 23 anos olha-nos de frente, confiante, rosto tranquilo, sem sorriso, como se casualmente fotografada (O filme da "simpatia", 1946, p. 5) (Figura 1). A indumentária arrojada, prática para o inverno naquele estúdio precário, denota profissionalismo e apela ao respeito público. Noutras fotos a apresentação será distinta (Bárbara Virgínia realizadora do filme "Três dias sem Deus", 1948; Pinto, 1951, p. 12; Ribeiro, 1983, p. 543).

Dirigia o seu filme de ficção Três dias sem Deus. Era o ano de 1946 e a ousadia assenta bem à primeira realizadora de uma longa metragem em Portugal e uma das primeiras a nível internacional (Cunha, 2000). Foi autora ainda de uma peculiar curta nesse mesmo ano, Aldeia dos rapazes: Orfanato Sta. Isabel de Albarraque.

Três dias sem Deus seria exibido no primeiro Festival de Cinema de Cannes em 1946 (Sarmento, 1946, p. 5), assinalando a única presença de uma mulher na direção a solo de uma longa metragem' (conforme se pode verificar no site do Festival de Cannes, na secção "Sélection officielle 1946: en Compétition" ${ }^{2}$ ). É a Leitão de Barros que Bárbara atribui o encorajamento para concorrer, competindo ele mesmo com Camões, um épico nacionalista, na linha da propaganda fascista do SNI (Secretariado Nacional de Informação) 3 e por este premiado (Ribeiro, 2010, p. 25; Vieira, 2015, pp. 59-60).

Cerca de 40 anos depois, e durante uma entrevista no Brasil, Bárbara declararia a Leonor Xavier: "sempre fui emancipada, aos 15 anos já era feminista, acho que temos os mesmos direitos que os homens têm" (Xavier, 1987, p. 18). Rica em informação, a peça

\footnotetext{
' No mesmo festival foi apresentada outra longa metragem de autoria feminina, De røde enge (Os prados vermelhos). A realizadora Bodil Ipsen co-autorou com Lau Lauritzen este filme. Ela e ele tinham nacionalidade dinamarquesa.

${ }^{2}$ Retirado de http://www.festival-cannes.fr/fr/archives/1946/inCompetition.html

3 O SNI, criado em 1944, sucede ao SPN, Secretariado de Propaganda Nacional, com atividade iniciada em 1933.
} 
contém, face a outras fontes, divergências que nos causaram dificuldades interpretativas, frequentes na construção biográfica, constituindo-se como outro ponto marcante neste percurso investigativo.

Nascida em família de classe média, de mãe dona de casa e pai oficial da marinha participante no 5 de outubro ${ }^{4}$, Bárbara Virgínia desenvolveu um trabalho artístico diversificado, pleno de aspetos contraditórios. Por um lado, revelou precocidade nos palcos e na rádio, assumiu ousadia quanto a papéis de género no campo profissional e na vida privada. Criou depois registos inovadores na cinematografia, tentou explorar o surpreendente em quotidianos incomuns. Por outro lado, seguiu roteiros e ideários do tradicionalismo luso, com alguns traços coloniais e de moral sexual/reprodutiva conservadora. Traços, como é sabido, não exclusivos da ideologia fascista mas assumidos também por setores da chamada oposição republicana. Os livros da sua autoria, já de uma fase madura, condensam a etiqueta endereçada a mulheres da classe média. Constituída e inserida a nova família numa vida social confortável em São Paulo, acabará por deixar a vida artística.

A memória da família regista que Bárbara Virgínia terá destruído, nas décadas recentes, parte significativa das fotografias e papéis sobre essa vida, por provável mágoa na sua rememoração.

A única cópia de Três dias sem Deus em Portugal encontra-se muito deteriorada. No Brasil não conseguimos localizar outra que, supostamente, esse país recebera. Dos 102 minutos iniciais, restam 22 de filme em suporte fragmentado e emudecido. Rasura dupla: do tempo, traduzido em decomposição; da curadoria, por omissão de preservação. Note-se que apagada ficou assim a banda sonora executada ao piano pela realizadora (Sarmento, 1946, p. 5).

Daquela fotografia, de simbolismo forte, partimos. Passamos, emocionalmente, pela frustração de encontrar tão pouco sobre quem preenchera audiências, suscitara atenção mediática, marcara a dianteira de cronologias, ocasionara admiração, mas também rejeição nos meios artísticos e intelectuais. Propusemo-nos abordar dificuldades, vazios e deleções como possibilidade para soltar fios de pesquisa e alinhar reflexões que, criticamente, integrassem e alimentassem esta narrativa.

\section{DA TEORIA, A MOLDURA}

O cruzamento de estudos da cultura, de género e da história estimularam o questionamento de vazios e de tensões dentro de um terreno hermenêutico comum.

Neste estudo de caso relacionámos, muito particularmente, as abordagens de Linda Alcoff (1994, 2005) ao género, à construção da identidade e da política identitária, e ainda às relações entre cultura, poder e feminismo. Considerando a faceta biográfica, pretendemos destacar o conceito de subjetividade acolhido por Alcoff (1994, 2005),

\footnotetext{
4 Segundo dados na Biblioteca Central da Marinha - Arquivo Histórico, foi oficial da Marinha de Guerra, sofreu incidente em serviço pouco antes de 5-10-1910, falecendo como inválido de guerra em 1945; aderiu ao apelo para se juntar às forças revoltosas da República; viria a ser condecorado por serviços prestados em S. Vicente, Cabo Verde, em 1919, após o que é reformado.
} 
partindo da problematização de Teresa de Lauretis (1984). Assim, não buscámos os traços da coerência formal, suposto garante de veracidade. A subjetividade foi antes questionada enquanto realidade fluída, dinâmica, historicamente situada e socialmente construída, "aberta à alteração pela prática auto-analisadora" (Alcoff, 1988, p. 425), num processo de interpretação política e de orientação para a ação. Acolhemos sim as incoerências entre episódios ou narrativas de terceiros, recusando uma veracidade mítica. Tão pouco abordámos a subjetividade como oposição entre interioridade e exterioridade da pessoa. Ela:

pelo contrário, é o efeito da interação, a que chamo experiência; e portanto é produzida não pelas ideias, valores externos ou causas materiais, mas pelo envolvimento pessoal, subjetivo de uma pessoa nas práticas, discursos e instituições que conferem significação (valor, significado e afeto) aos eventos do mundo. (de Lauretis, 1984, p. 59)

Moldada pela posicionalidade relativa no contexto social, a identidade mostra-se marcada por classes, raças, géneros e relações de poder históricas que tecem esse contexto. Por sua vez, e dentro das margens de manobra possíveis, a posição subjetiva constrói-se a partir das experiências vividas. Concebemos o sujeito da nossa análise relacionalmente, dentro deste quadro teórico em que o género é uma importante dimensão analítica, tanto lugar de construção e de interpretação de significados como ainda lugar para expressão de poder e atuação política.

A agência individual de Bárbara e a dos seus grupos sociais de pertença, os processos através dos quais investiu em feminilidade de forma ambivalente (Skeggs, 1997) ou evidenciou as suas disposições de pessoa cultivada (Bourdieu, 1979), a entrada na profissionalidade de um cinema pouco industrializado e num campo profissional ainda em formação, foram tidas em conta numa configuração onde se inscrevem género e classe como dimensões notórias assentes no contexto nacionalista-colonialista português (Ribeiro, 2010).

Atendemos ao momento histórico desta história singular. A iniciação de Bárbara no campo cinematográfico, como atriz primeiro, como realizadora depois, fez-se no período em que a produção permanecia controlada ideológica e financeiramente pelo Estado Novo de Salazar. Esse era o papel da Secção de Cinema do Secretariado da Propaganda Nacional (SPN), criado em 1933, então reorganizado como SNI (Secretariado Nacional de Informação, Cultura Popular e Turismo), um e outro dirigidos por António Ferro até 1949.

O projeto político inicial de Ferro - a Política do Espírito -, submetia arte, cultura e algum entretenimento folclorizado, dito de cultura popular, à propaganda do regime. Mudanças estéticas, morais e políticas convergiriam numa arte nacionalista, prescrevendo uma "fachada impecável de bom gosto" que especialmente proviesse às "necessidades espirituais das classes trabalhadoras" (Ferro citado em Ribeiro, 2010, pp. 39-40). Uma "estetização da política" (Ó citado em Ribeiro, 2010, p. 39) devia avançar no domínio simbólico. 
À disciplina do gosto associou-se o protecionismo para uma produção que, não sendo demasiado recente, carecia de dimensão industrial. A introdução, desde 1927, de quotas para exibir filmes nacionais levara ao aparecimento de curtas - que precederiam a projeção das grandes fitas estrangeiras - contudo consideradas sem valor artístico pelos zeladores institucionais do gosto. As dificuldades setoriais ao nível tecnológico, de formação de artistas e técnicos, levariam à pressão política junto do Estado, protagonizada por realizadores, jornalistas e críticos - facetas acumuladas num pequeno círculo de homens. Estes apelaram ao apoio oficial para a produção fílmica, nomeadamente através de estúdio qualificado para a produção de filmes sonoros (Ribeiro, 1983). Entretanto a exportação de filmes permaneceria sem sucesso (Ramos, 2012).

Seria preciso já esperar pelo fim do regime para que outra mulher, Margarida Cordeiro, autorasse, com António Reis, uma longa metragem. Só a partir da década de 1980 a autoria feminina, permanecendo excecional, se torna realidade (14\% nas três últimas décadas) (Pereira, 2013, p. 107).

Esta é a moldura breve composta para a análise sócio-biográfica da mulher cineasta, artista.

\section{ToRNAR-SE BÁRbARA Virgínia}

Bárbara frequentou o Conservatório Nacional, em Lisboa (Ramos, 2012, p. 453), estudando intensivamente entre 1940 e 19435, segundo Gentil Marques que assinou como

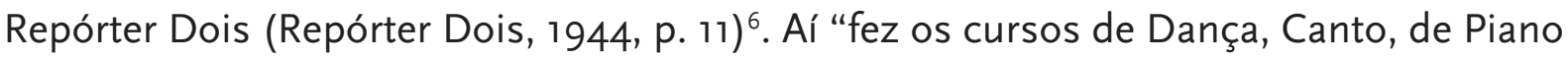
e de Teatro", sendo aluna de Alves da Cunha em teatro (Ribeiro, 1983, p. 544) e de Pedro de Freitas Branco em piano (Xavier, 1987, p.18).

Apresenta-se publicamente, nessa entrevista, como investida pelas predecessoras femininas (mãe e avó) de substancial capital cultural e social (Bourdieu, 1979). Refere o círculo de relações artísticas e culturais da família de origem - onde se incluíam Júlio Dantas e o mestre Rey Colaço -, e as frequentes viagens na infância (Xavier, 1987, p. 18). Das redes que ela própria construirá, falaremos depois.

É, contudo, por escolha própria, não por costume, que Maria de Lourdes Dias Costa (1923-2015) - nome civil - adota os nomes próprios da mãe, avó e bisavó, que transmitirá à filha. Usará Bárbara Virgínia para a sua persona adolescente emergente e para nome artístico, depois de fortemente confrontada por membros do lado paterno da família. Estes, diferentemente da mãe e do pai, censuravam a sua exposição pública como imprópria para uma jovem do seu estrato social (Repórter Dois, 1944, p. 11). Este é, provavelmente, o seu mais persistente exercício de manobra face a um sistema opressor (Alcoff, 1994, 2005), associando autonomeação e posicionalidade: renomeia-se como sujeito ativo, em oposição às expectativas para o seu desempenho de género; no processo crítico de uma biografia em construção, torna pública a sua posicionalidade reinscrevendo-se na linhagem familiar com a qual se identifica (de Lauretis, 1984).

\footnotetext{
${ }^{5}$ Datas confirmadas pelo processo académico de Bárbara Virgínia no Conservatório Nacional, 1940-1943.

${ }^{6}$ Segundo nota autógrafa de Bárbara Virgínia no seu recorte desse periódico.
} 
Conhecida desde a adolescência como diseuse, divulgada por João Villaret, foi voz da Emissora Nacional (Sarmento, 1946, p. 5) nessa qualidade e como cantora lírica. Tornou-se artista de teatro e de cinema na vida adulta inicial (Xavier, 1987, p. 18; Matos, 2000, pp. 74-86).

A partir das fotos de estúdio e do qualificativo de "simpatia" nos periódicos (Pinto, 1951, p. 12; O filme da "simpatia", 1946, p. 5; Bárbara Virgínia realizadora do filme "Três dias sem Deus", 1948, capa; Ribeiro, 1983, p. 543), entendemos que Bárbara geriu a sua imagem entre as fronteiras da moral sexual vigente no seu meio e as do arrojo artístico e privado, colhendo não só apreço, mas também admoestação. Esses eram os arranjos performativos, resultantes da negociação individual e social de mulheres de classe média, que sintetizavam no glamour da apresentação expressões subjetivas de feminilidade, desejabilidade e respeitabilidade (Skeggs, 1997).

Acaba por ir trabalhar para o Brasil em 1952, com um primeiro contrato com a Tupi TV e a Rádio e, segundo a própria, a convite de Saladini, adido cultural do Brasil em Portugal (Xavier, 1987, p. 18; Pereira, 2016). Ao final de seis anos de estadia viaja por Angola e Moçambique. No Brasil se fixa e constitui família: casa perto dos 40 anos e é mãe aos 52. Reside a maior parte desse tempo em São Paulo, onde falece a sete de março de 2015, com 92 anos7.

A emigração para o Brasil refletiu, acima de tudo, expectativa de libertação dos constrangimentos vividos em Portugal, sem apoio para projetos cinematográficos e sem ligação positiva à restante família. A mãe, com quem tinha grande proximidade, viúva desde $1945^{\circ}$, acompanhou-a até ao Brasil e aí permaneceu, sua conselheira artística de eleição (Figura 2).

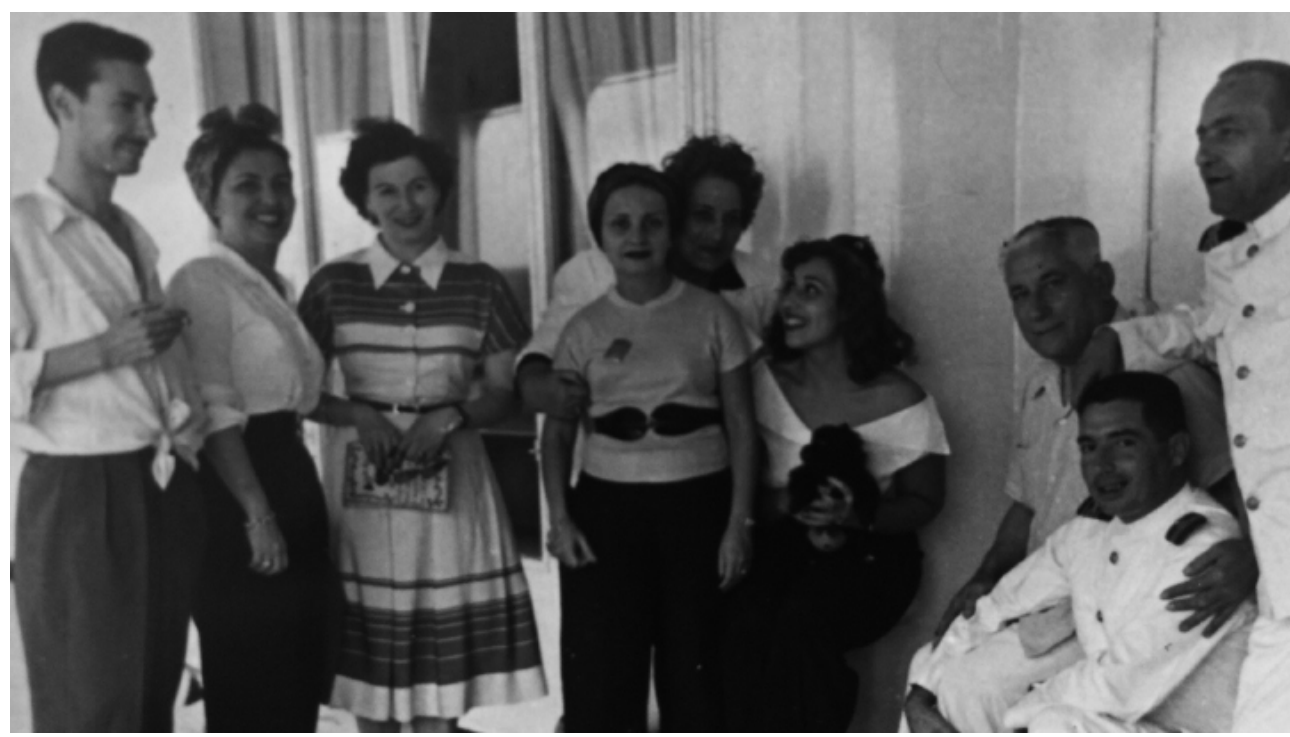

Figura 2: Bárbara e mãe a bordo do Vera Cruz com destino ao Brasil

7 E não a oito como a imprensa portuguesa reportou, ver a notícia "Morreu a primeira realizadora portuguesa de cinema" (2015).

${ }^{8}$ Ver nota 4; faleceu em 1945 (arquivos da Marinha e da Sétima Conservatória do Registo Civil de Lisboa) e não aos 11 anos de Bárbara conforme declarações publicadas por Leonor Xavier. 
Contudo, o nome de batismo foi abandonado mesmo na vida privada e ignorado pela quase totalidade das suas relações. Já o nome profissional foi registado, secundariamente, pelos serviços de estrangeiros do Brasil9.

\section{DA ENTREVISTA IMPOSSÍVEL AO ENCONTRO NOS DOCUMENTOS}

Bárbara morreu quatro dias antes da coautora deste artigo, Luísa Sequeira, ter chegado a São Paulo para a entrevistar. Andar no encalço de Bárbara foi tarefa iniciada vários meses antes. O encontro pessoal, já impossível, foi então marcado nos seus papéis, doados pela filha. Estes consistiam em recortes de jornais, destinados talvez a um álbum, e fotografias dispersas dela própria, livros de etiqueta da sua autoria, registos dos serviços de emigração. A isto se juntaram recortes oferecidos por uma fã brasileira que preferiu permanecer anónima.

Peças importantes que lhes juntámos foram Anto (Vianna \& Muller, 1950) - o argumento de um filme rejeitado pelo SNI - e a entrevista de Wiliam Pianco e Ana Catarina Pereira, último registo ao vivo de Bárbara, então com 89 anos. Analisámos ainda os seus dois filmes e documentação relacionada depositados na Cinemateca Portuguesa (ANIM, Biblioteca e Arquivo Fotográfico), assim como registos vários sobre a família.

Antes ainda da rejeição de Anto, declarou-se magoada ao ser preterida na realização de documentário, que alegadamente idealizara e propusera, no que insistirá em declarações recentes. Proporcionada pela invulgar queda de neve em Lisboa em 1945, a ideia adveio enquanto atuava no filme Sonho de Amor (Porfírio, 1945). Note-se que Carlos Porfírio, conhecido como pintor, etnógrafo e editor do número único da revista Portugal Futurista (Ramos, 2012, p. 316; Marreiros, 2001, pp. 423-424), realizaria outro filme com argumento de Gentil Marques, o qual se cruzará com Bárbara Virgínia como referiremos.

Assim explicou Bárbara o interesse pelo incomum no quotidiano:

nunca penso que não tenho dinheiro, mas hoje eu pensei: não tenho dinheiro para dirigir um documentário. Gostaria de fazer um documentário sobre neve em Lisboa, e eles disseram: O que é que interessa a neve em Lisboa para um documentário? Interessa, nunca se viu nada disso. Interessava sim... interessava! Era uma novidade ... então alguém ouviu e fez a Neve em Lisboa, fez com um aspeto diferente do que eu teria feito na época mas me convidou, foi muito correto me convidou para apresentar, eu nunca tinha apresentado, eu fui como locutora... ${ }^{10}$

Foi, portanto, apenas a voz-off no filme de Raul Faria da Fonseca - neste momento igualmente sem som.

\footnotetext{
9 Documentos de migração de Maria de Lourdes Dias Costa, 1955; certificado 1984302, registro 457341, Arquivo Público do Estado de São Paulo.

${ }^{10}$ Gravação não publicada de entrevista a Bárbara Virgínia realizada por William Pianco e Ana Catarina Pereira, em 2015.
} 


\section{A ESCRITA dE BÁRbara Virgínia}

Em Modas e Bordados publicou artigos, na Flama e no Século Ilustrado foi autora e editora (Xavier, 1987, p. 18). Entendemos não buscar essas publicações, conhecida a ausência de referências analíticas para essa documentação e pela relevância que quisemos dar à sua cinematografia. Os livros escritos foram alvo de atenção.

Enquanto no Brasil e entre 1970 e 90, Bárbara Virgínia autorou quatro manuais de etiqueta sobre papéis femininos, dirigidos ora a "mulheres", ora a "executivos", ora a "teenagers". As suas editoras, Paulinas e Loyola, pertenciam a círculos católicos ideologicamente influentes (Hallewell, 2005, pp. 707-708). Palavras e imagens são aí mobilizadas para advogar o aperfeiçoamento moral e cívico das famílias de classe média que incluíssem detentores de capital ou gerentes. Das mães se esperava que agissem exemplarmente e que conseguissem, por influência familiar, amenizar as questões laborais e sociais.

\section{Primeira longa Metragem: O ARRojo E OS EMbates}

O nome de Bárbara será relembrado como autora de Três dias sem Deus, estreado em 1946. Relevante, nessa época, é o desfasamento entre o projeto político ambicioso de uma indústria cinematográfica nacional e os resultados efetivos, numa "década que viria a dar ao cinema português quarenta e cinco novos filmes e muito pouco cinema" (Alves Costa citado em Ribeiro, 2010, p. 29). O projeto dirigia-se ainda a superar géneros populares com muito público mas de baixo gosto, tipicamente as comédias cinematográficas e o teatro de revista.

Comecemos por relevar a intencionalidade do filme, não considerada até ao momento. O título baseia-se na referência católica ao período dos três dias passados entre a morte e a ressurreição de Cristo, deixando a terra entregue a si própria, sem deus. Analogamente, médico e padre ausentam-se por três dias, deixando a aldeia entregue à superstição e à irracionalidade descontroladas. À relevância da religiosidade, que atravessa todo o filme, voltaremos adiante.

Raul Faria da Fonseca, por quem fora preterida na realização de Neve em Lisboa de 1945, fez a planificação da filmagem de Três dias sem Deus (Bárbara Virgínia, 1946). O argumento nasceu do texto Mundo Perdido... de Gentil Marques" - aparentemente por publicar pois, não consta em nenhuma biblioteca portuguesa. Esse autor produziu documentários e extensa obra literária, incluindo romances baseados nos enredos de filmes a que assistia. O que se conhece seu é uma "equência dialogada, base da planificação", depositada na Cinemateca, com a menção "inspirada no romance". Os diálogos eram de Fernando Teixeira, a produtora a Invicta Filmes Independente, de Lisboa, a distribuidora, a Ibéria Filmes (Três dias sem deus, 1946, p. 6). Com rodagem iniciada em fevereiro de 1946 nos estúdios da Cinelândia, a película seria projetada em público seis meses depois.

No tocante às competências, afigura-se-nos muito provável que Bárbara Virgínia aprendesse o métier de cineasta representando sob a direção de Porfírio, formado em Paris, cidade onde viveu alguns anos para além de Roma (Marreiros, 2001).

\footnotetext{
"Correntemente citado assim, usava por vezes no nome literário do meio o apelido Esteveira.
} 
Três dias sem Deus estreou em Lisboa a 30 de agosto de 46 no Teatro Ginásio ${ }^{12}$, recebendo críticas favoráveis, em geral, na imprensa nacional e local'33 (Lourenço, 1946, p. 8; Três dias sem deus: esta noite no Ginásio, estreia de um novo filme português, 1946, p. 9; Visor 42, 1946, p. 5). Localizámos registos da sua exibição em Santarém, por dois dias, em novembro desse ano (Moreira, 2013, p. LIV).

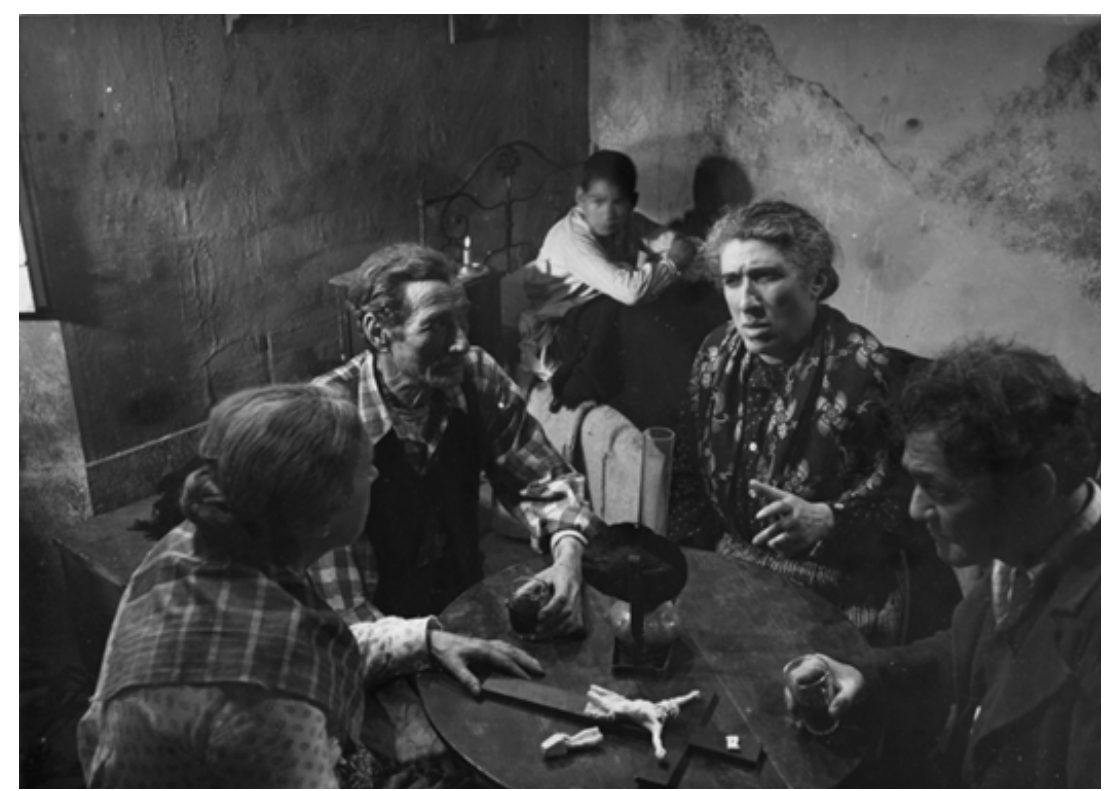

Figura 3: Cena de Três dias sem Deus, Bárbara Virgínia, 1946. Aldeões suspeitam da recém-chegada professora e do pai da família abastada Fonte: Coleção Cinemateca Portuguesa, Museu do Cinema

Avançamos uma análise detalhada do argumento e da sua receção pela crítica. Fazemo-lo, pelo estado das imagens e para elucidar aspetos até aqui não considerados mas relevantes.

No argumento, uma jovem professora, carinhosa, recém-chegada a uma aldeia - situada em baixo -, é mal recebida pelas famílias rurais pobres face à sua postura citadina (Figura 3). Na escola opõe-se a que uma idosa use uma mezinha para tratar um aluno, insistindo no acompanhamento pelo médico. Entretanto, padre e médico haviam deixado a aldeia. Retida por um imprevisto temporal noturno, aloja-se na casa acastelada no topo de um monte, da família de classe mais alta - em cima -, cujos menina e menino ensinava na escola. Ao fazê-lo, evita aliás regressar à aldeia onde a esperava a hostilidade, agora aberta, de aldeões que haviam proibido a ida das crianças às aulas. Precipitam-se então os acontecimentos e, dentro da atmosfera fantástica que se adensa, apresenta-se um drama familiar, em paralelo com o drama local. A mãe, há muito isolada no quarto entre a doença mental e a paralisia, não mais aparecera em público. $O$ rumor na aldeia atribuía esse estado a tentativa de homicídio pelo marido, acusando-o ainda de um incêndio na igreja.

\footnotetext{
${ }^{12}$ E não em 1945, como registou Félix Ribeiro (1983).

${ }^{13}$ Alguns recortes de imprensa na nossa posse estão ainda por identificar plenamente, citam-se aqui apenas os de referência mais completa.
} 
Ressaltamos desde já que, na escola e junto dessa família, a professora encarnava o ideal da mulher cuidadora de inspiração católica que o regime político alimentava (Pimentel, 2011). Além de contrariar crenças primitivas, demonstrava uma diligência moralmente guiada face à distância emocional do pai em relação a filhos e esposa, esta entregue aos cuidados da criada pessoal. A figura do pai não anda longe do cliché cinematográfico do Estado Novo para o republicano vencido pelo novo regime: homem instruído, com dinheiro, afastado do povo, não praticante do culto. A mãe é personagem duplamente estigmatizada: o descontrole das artes corporizado na demência; a fonte do mal corporizada no género. Esta expiação pela família quebrar-se-á com o clímax final ao ser percebida pela aldeia a razão do seu estado.

Nessa noite forma-se uma turba de aldeões para arrombar e incendiar o castelo, sob a acusação de estarem os proprietários possuídos pelo demónio. Mas, pouco antes, instalara-se uma tensão entre a professora e o senhor da casa. Segundo a "sequência dialogada", o pai insiste para que ela se mude para sua casa para cuidar do filho carente. Face à sua recusa, admite o desejo "sou eu... sou eu que preciso de si, da sua mocidade", e obtém a resposta “não, deixe-me. Deixe-me por favor...". Durante a invasão, a turba irracional empunhando tochas, cliché para as movimentações populares no tempo da república, é surpreendida ao encontrar a família reunida a rezar por iniciativa da professora. Espanta-se mais ao encontrar a esposa recuperada, por reversão psicológica frente às chamas que carregara.

É a professora que, providencialmente, põe cobro à ira justiceira e repõe a ordem. Contudo, apesar de culta e devota, carece de legitimidade face à aldeia. A normalidade na escola será reposta após o regresso do médico e do padre, autoridades morais e patriarcais subordinantes (Figura 4).

Do que resta da película, alinhando com Marisa Vieira (2009) e precedentemente com Félix Ribeiro (1983), entendemos que Bárbara Virgínia criou um ambiente escuro, entre sonho e realidade, tanto na cenografia como nos locais naturais. Construiu suspense, intensificando a dramaticidade da representação com imagens de alto contraste, a preto e branco, com profundidade de campo, sombras profundas e grande recorte de luz. Com planos fechados produziu retratos psicológicos das personagens, assombradas por fantasmas e encerradas em medos.

Sinalizamos, como traços marcantes desta narrativa, algumas analogias com filmes ideologicamente alinhados com o regime. Na linha de Patrícia Vieira (2005) e Carla Ribeiro (2010), sustentamos assim que a leitura das obras deste período carece de abordagem ao simbolismo de enredos, personagens e composição de cenas e retratos e que estes, mais do que indivíduos ou grupos sociais, nos devolvem sobretudo estereótipos. Fazemo-lo também para ressaltar, em particular, dissonâncias impressas neste trabalho de Bárbara Virgínia. É o caso do seu olhar sobre o sítio da exclusão e os tipos sociais de uma ruralidade escura, atrasada, simbolicamente assentada em baixo, mostrando, contudo, cruamente a pobreza associada à ignorância. Já a professora, a que acede e liga ao lugar privilegiado em cima, empenha-se e persevera na expectativa de mudança pela educação e pela conciliação social, ideias com reverberações republicanas. 


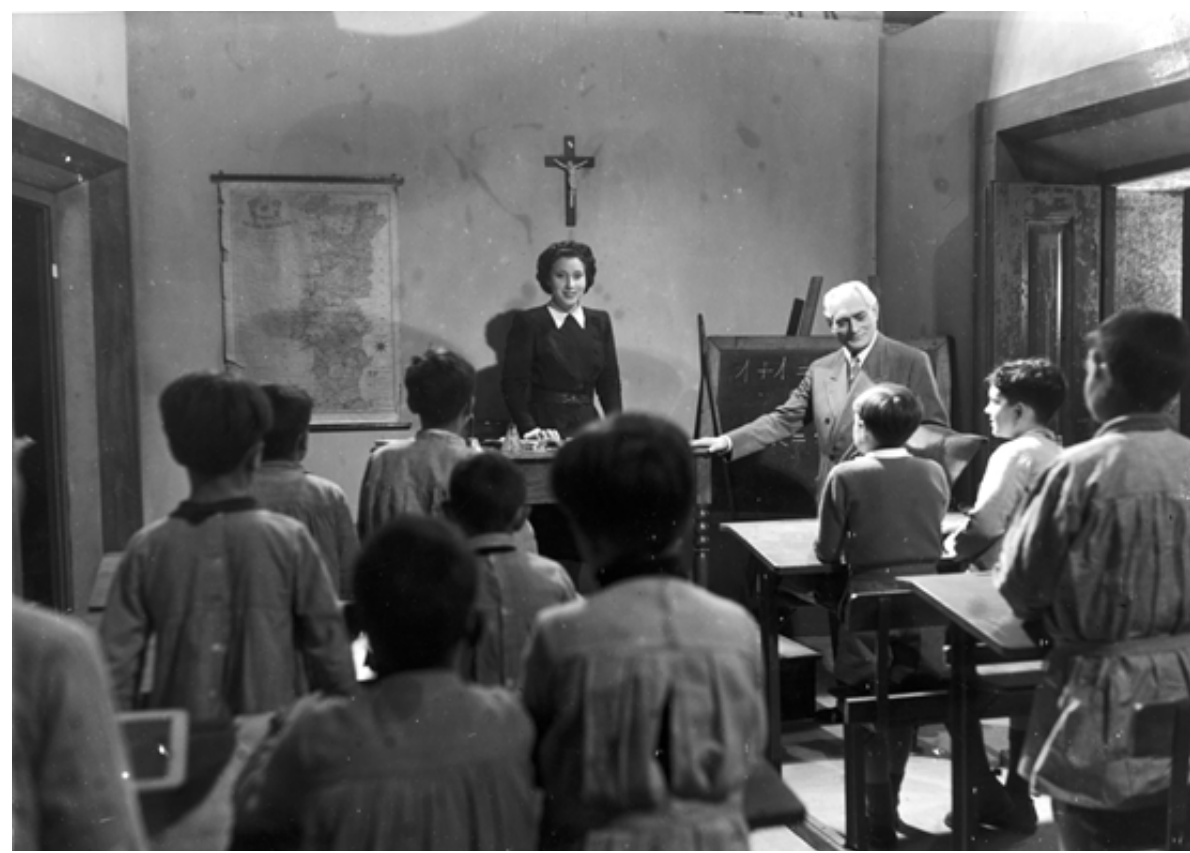

Figura 4: Cena de Três dias sem Deus, Barbara Virgínia, 1946. A escola Fonte: Coleção Cinemateca Portuguesa, Museu do Cinema

O sítio do privilégio, a casa acastelada da família proprietária, co-habitada por criadas e criados, é igualmente escuro, frio de emoções, com pontos de intensa iluminação centrada em rostos, especialmente no da professora. Se não é um espaço urbano, na tradicionalista dicotomia campo-pureza versus cidade-perdição, é ainda assim penalizado. Será abalado pela irracional vingança dos pobres, superada apenas pelo fogo comedido das velas e pela prece, a qual apazigua e junta os dois grupos.

\section{Publicidade e Receção a TrếS Dias Sem DeUs}

Feita esta análise, crer-se-ia que a obra reunia os ingredientes para ser bem recebida pelos setores fechados e conservadores da sociedade portuguesa. Muitas peças se escreveram, algumas frisando a adesão da assistência (Lourenço, 1946, p. 8; Sylvan, 1946, pp. 22-23; Visor 42, 1946, p. 5; Três dias sem deus: esta noite no Ginásio, estreia de um novo filme português, 1946, p. 9).

Contudo, tanto estética como politicamente - referimo-nos ao espetro amplo das relações de poder que envolve a produção cultural, as práticas de fruição artística, as ideias recebidas, formadas e difundidas no processo - houve lugar à expressão de opiniões diferentes, mesmo frontalmente divergentes. Comecemos pela publicidade.

Antecipando a estreia, dois anúncios de diferentes dimensões suscitavam leituras particulares: em primeiro lugar, respeito religioso pela cruz traçada a negro dentro da qual se inscreveu o texto publicitário; em segundo, o orgulho nacionalista por um filme "100\% português", menção no subtítulo, num pós-guerra notório noutras páginas desses jornais; e em terceiro, o apelo à diversão suscitado pelo quebra-cabeças com solução premiada. Num artifício publicitário, a empresa distribuidora, interpelando a 
inteligência de quem lia, logo adiantava a solução: sério, mas não para intelectuais, era a chave subtextual (Três dias sem deus: filme 100\% português dirigido por Bárbara Virgínia, 1946a, p. 3; Três dias sem deus: filme 100\% português dirigido por Bárbara Virgínia, 1946 b, p. 9). Não conseguimos determinar a que atribuir o caráter devocional daquela publicidade, sabemos apenas que o único financiador do filme era um comerciante de Lisboa, comanditário e financiador da Invicta Filmes Independente ${ }^{14}$ (Ribeiro, 1983, p. 544). Localizámos ainda a existência de vinhetas evocativas do filme ${ }^{15}$, usando o grafismo dos cartazes publicitários, aparentemente destinadas à expedição postal (Figura 5). No logótipo parece ler-se "Tradição". Esta prática trouxe-nos à memória as recolhas de fundos para as missões católicas nas colónias, ainda em vigor nos meados do século passado. Outra publicidade inseriu-se em anúncios de composição gráfica corrente (Um novo êxito do cinema português: Três dias sem Deus, 1946, p. 3).

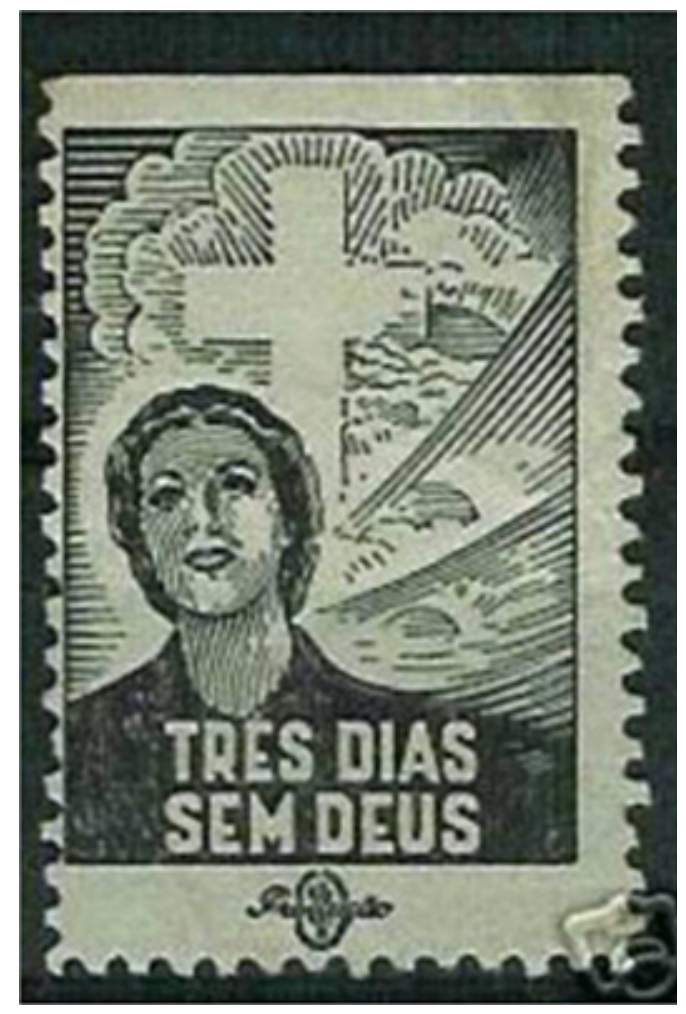

Figura 5: Vinheta alusiva ao filme Três dias sem Deus em formato de selo postal Fonte: https://www.delcampe.net/fr/collections/item/45580603.html

À estreia assistiram as conhecidas figuras do cinema de então, realizadores e prescritores do cânon cinematográfico do regime: António Lopes Ribeiro e Chianca de Garcia, críticos de cinema na imprensa também, Leitão de Barros e Brum do Canto. Nomes grados do pequeno círculo a que anteriormente aludimos, unia-os uma formação académica artística e a vontade de impulsionar um novo cinema para o estado-novismo.

\footnotetext{
14 Tratava-se de Felisberto Felismino, conhecido como o representante de uma marca de canetas de tinta permanente.

${ }^{15}$ Localizada na página web da Delcampe Net com a menção de ser vinheta com erro de perfuração. Retirado de https:// www.delcampe.net/fr/collections/item/45580603.html
} 
Pretendiam o abandono das velhas produções que, alegavam, não seguiam o gosto cultivado nem o domínio técnico reclamados pelo organismo tutelar do cinema do SPN, do qual faziam parte (Ribeiro, 2010, pp. 20-21).

No campo da crítica, passemos a uma apreciação desaprovadora para seguirmos com outras de diferente teor. O jornalista António Lourenço (Lourenço, 1946, p. 8) detalha as suas notas no matutino $O$ Século imediatamente após a estreia ${ }^{16}$. Elogia o trabalho iniciante, com "diferentes formas de expressionismo". Aponta-lhe como virtude "o primado da imagem: expressão e movimento com o mínimo de palavras", a estética apurada que se demarca dos filmes "popularuchos", "com recurso a novos estilos de feitura". Reprova que Bárbara acumule direção e representação e adverte-a. Quanto ao argumento, refere o "recorte de um sombrio agregado humano", onde as "personagens [estão] vergadas sob o peso de uma tragédia". Tanto as superstições como as "absurdas crendices" daquela "gente boa mas rude", davam, em sua opinião, "magníficos elementos de inspiração" para um "primeiro caso de profundidade psicológico [sic] do cinema português". Deixa assim implícito que Bárbara falhou essa oportunidade porque, alega, alterou a intenção original de Gentil Marques, ausente da rodagem. Que a questão foi polémica depreende-se do Esclarecimento (Esclarecimento, 1946, p. 9) ao lado do referido anúncio com a cruz no Diário Popular. Esclarece-se que Raul Faria da Fonseca é o responsável pela sequência cinematográfica, não pela modificação introduzida ${ }^{17}$. Note-se que na interpretação desse texto divergimos de Lisboa (2016, p. 52) que toma como autor Fonseca e não Marques, cremos que apoiado na referência ao facto de Bárbara ter sido chamada em substituição desse realizador experimentado. De novo, e voltando ao artigo de António Lourenço, o resultado da decisão da realizadora foi que, apesar da riqueza do argumento e da "riqueza de caráter e objectividade de efeitos" proporcionados por Fonseca, as "características de algumas personagens e o sentido das suas reações" acabou deturpado (Lourenço, 1946, p. 8). "Um exemplo flagrante" está no facto de a protagonista, "por carência de definição psicológica", deixar no público a dúvida se as suas ações se dirigem a condenar as superstições, "num reflexo do seu dever de professora ou o pronuncio de um amor pelo pai do garoto". Mas António Lourenço não discorda só, prescreve: frente ao homem "que todos repudiam", requeria-se "uma figura de professora da grandeza moral de um símbolo que personificasse, umas vezes a consciência, outras, o anjo da guarda ou um coração iluminado pelos mais belos sentimentos de ternura e de cristandade, que a Providência atirara para aquele lugarejo para tornar o pai do garoto feliz e conduzir ao arrependimento todos os que o vaiavam". E avança: "a máscara devia definir, com maior clareza, os tormentos em que o seu espírito se debatia". Se é conhecido o diálogo arquivado e há registo de várias notas com alterações, as imagens e o som dessa contestada sequência não chegaram aos nossos dias.

\footnotetext{
${ }^{16}$ António Lourenço colaborou com os periódicos Movimento e Mundo Gráfico (ver Mangorrinha, 2014).

17 "Para os devidos efeitos se esclarece que na publicidade relativa ao filme Três dias sem Deus faltou mencionar o facto de a respetiva planificação inicial ter sido posteriormente alterada sem intervenção do autor, que se encontrava ausente, cabendo portanto a Raul Faria da Fonseca as responsabilidades do argumento (sequência cinematográfica), naquilo em que este não foi prejudicado por aquela circunstância" (Esclarecimento, 1946, p. 9).
} 
Podemos contudo depreender que a falha adviria da ausência de repúdio ostensivamente corporizado, já que segundo o argumento contestaria: "deixa-me, deixa-me". A fácies contraída da professora permitia, aliás, ler a recusa.

Falhas menores, como ligações entre cenas ou de luz, não impediram a aprovação e os aplausos entusiasmados da plateia, considera por fim. Contudo, em "Nota Final" avisa: do filme que vai representar o país em Cannes, "rasgando novos horizontes ao cinema português" espera-se que revele "outras paisagens humanas e outros cenários de Portugal - mas com senso e prudência! "8" (itálico acrescentado pelas autoras). O senso nacionalista temia que uma imagem crua da pobreza e do atraso fosse mostrada lá fora. Já a vigilância patriarcal, exigindo forte rechaço face ao avanço do pai, manifestou-se desproporcionada e resultou numa ostensiva reprimenda pública.

O crítico investiu-se de autoridade moral perante uma representação problemática em competição internacional por esta não seguir a bitola da narrativa edificante e exemplar. Se a Bárbara intérprete lhe mereceu reparos, é a Bárbara realizadora que condena e admoesta. A reprimenda não parece resultar da acumulação de papéis numa só produção, mas antes da entrada de uma mulher num campo profissional de fresca constituição e de recorte masculino, alegando a sua fragilidade e inexperiência. Lembremos que de mulheres de bem se esperava apenas o trabalho reprodutivo e se exigia o abandono do produtivo (Salazar citado em Vieira 2015, p. 173).

É ao assumir o papel criativo com maior poder de decisão que a jovem realizadora corporiza uma afronta à conformação de género no campo do cinema, e não só. Nesses anos o crescimento no número de assalariadas viria a parar, aspetos da sua condição como trabalhadoras e cidadãs viriam a agravar-se. Mudanças positivas a esse quadro registar-se-iam bem mais tarde, nos anos 60 (Pimentel, 2011, pp. 74-81).

Em suma, menorizando embora as falhas técnicas, como outros críticos, António Lourenço condena a realizadora/atriz por não se constituir como responsável pela consciência do pai de família. E dentro da lógica patriarcal, face à transgressão dele, expõe-na a ela à condenação pública.

Este desvio de Bárbara ter-se-á acumulado com posicionamentos sancionáveis no contexto histórico e social dos seus vinte anos, o que a viria a marcar na forma como avalia a censura ao seu trabalho, como veremos.

Destacamos agora o divergente olhar e diversa leitura de dois outros críticos, um demonstrando uma sensibilidade estética mais avançada, ambos elogiosos da presença de uma mulher atrás das câmaras. O Visor 42 (1946, p. 5) considerou Três dias sem Deus um "filme sério, de alto romantismo dramático". Lamentou apenas que fosse "excessivo nos efeitos", esteticamente reprovando as "diferentes formas de expressionismo" que António Lourenço apreciara. Comenta com agrado a capacidade de "criar, evidentemente, um clima patético, até mesmo de horror, sobretudo de constante inquietação

\footnotetext{
${ }^{18}$ De forma contrastante com estas paisagens humanas, eufemismo para a aldeia de gente pobre e ignorante retratada em Três dias sem Deus, Leitão de Barros, num assomo de orgulho nacional, declarava em artigo no Mundo Gráfico: "qual o sítio mais bonito de Lisboa?" "Não respondo. Nem esta é pergunta que se faça a um 'Amigo de Lisboa'! Lisboa (...) não tem sítios feios" (ver Mangorrinha, 2014).
} 
emotiva", associando-o a Rebeca e O monte dos Vendavais, proporcionadores de "o mesmo frémito de espanto e terror". Recorda que Barbara Virgínia, "dirá, com inteira razão, que quis fazer uma tragedia rústica, e é desse angulo que o seu trabalho deve ser analisado". Referindo-se implicitamente à crítica de António Lourenço no vespertino do mesmo dia, recusa pronunciar-se sobre se "a exteriorização" acompanhou "sempre a análise psicológica" , se a modificação no argumento melhorou ou piorou o resultado. Sintetiza, afirmando um gosto mais moderno: "se quando atinge o tenebroso gostamos menos, reconhecemos, no entanto, que não deixa de ser uma imperiosa farsa dramática". De forma distinta de outros críticos, declara: "Barbara Virgínia mereceu, as flores que, no final, Ihe caíram aos pés, não, apenas, por que é uma senhora mas também por que é uma artista, no sentido mais lato da palavra". "Não deixa de ser audacioso e simpático ver uma senhora, trabalhando nos estúdios nacionais, como realizadora!". Elogia a representação dos vários artistas, "numa homogeneidade de interpretação ajustada às intenções da obra", a "fotografia de Tony" com "notáveis quadros", afirmando que "som, partitura, cenários, montagem, [demonstraram] uma técnica já adiantada". Registamos que Visor 42 era o pseudónimo jornalístico de Arthur Portela (Ramos 2012, entrada Heróis do Mar). Azinhal Abelho, a propósito da representação portuguesa em Cannes, "feita quase com homens" comentará enfaticamente, anos depois: "se não fosse a Bárbara até parece que as mulheres não entravam no cinema em Portugal" (Abelho, 1959, p. 52).

\section{UM ESQUeCido DOCUMENTÁRIo: AldeIA DOS RAPAZES}

Segundo os registos da Cinemateca Portuguesa, Bárbara Virgínia realizou ainda um segundo filme. Aldeia dos rapazes: Orfanato Sta. Isabel de Albarraque (1946) é uma curta-metragem sobre essa instituição católica. Quase desconhecida da crítica de cinema e despercebida para a investigação científica, consta em bibliografia de referência (Cruz, Ferreira \& Pina, 1989). O mau estado de conservação privou-a do som, tal como a longa. Juntamente com Jogo da Sardinha, foi exibida como prelúdio às exibições de Três dias sem Deus em Lisboa. Referem-se-lhe os jornalistas António Lourenço (Lourenço, 1946, p. 8) e António Sarmento (Sarmento, 1946, p. 5), tendo o primeiro atribuído erradamente a autoria de Jogo... a Bárbara e o segundo a José de Oliveira Costa. Visor 42 é concisamente aprovador (Visor 42, 1946, p. 5): "passaram como complementos 'Aildeia [sic] dos Rapazes' e 'O jogo da sardinha' de muito interesse".

Interessante é entender como, contrariando a convenção e a expectativa, a narrativa se centra nos meninos e não na instituição. Onde esperaríamos, talvez, tristeza e sofrimento, são dadas a ver brincadeiras infantis surpreendentes: alguns internados caraterizam-se para uma festa no orfanato masculino. Maquilham-se, usam vestidos e falsos seios e atuam como substitutos das - inexistentes - parceiras femininas de dança. Noutra cena, as crianças envolvem-se numa alegre luta de almofadas. Zéro de conduite, filme de Jean Vigo datado de 1933, e com uma semelhante cena de luta de almofadas, foi censurado por longo tempo em Portugal, mas também em França, sendo pouco provável que Bárbara o tenha visto. 
A realizadora adota nesta curta metragem perspetivas originais e demonstra domínio técnico: ocasionalmente há rapazes que, de forma íntima, olham diretamente para a objetiva; em imagens finais, um balde de água é atirado para a câmara no decurso de uma brincadeira. O tom geral é de uma fantasia e irreverência infantis, retratadas benevolamente.

Igualmente produzido pela Invicta Filmes Independente em 1946, Aldeia dos rapazes foi filmado em Albarraque, localização do orfanato masculino, mas também de algumas cenas exteriores de Três dias sem Deus. Provavelmente rodado rapidamente e sem guião - não arquivado na Cinemateca -, este documentário foi certamente produzido de forma mais livre. São conhecidas poucas referências à sua exibição e nenhuma lhe é exclusiva.

Esta curta não deve ser confundida com outras com o mesmo título principal, de Adolfo Coelho, produzidas sobre instituições de menores noutras localizações. A Aldeia dos rapazes da rua, de 1947, sobre a Casa do Gaiato do Padre Américo, foi um filme de enaltecimento dessa instituição, produzido pelo SNI. Passou ainda em aulas de catequese nos anos 60 e, segundo recordamos, na televisão, com características estéticas e de conteúdo em nada semelhantes à obra sobre Albarraque. Questões que haja sobre a autoria de Bárbara, as que nós colocamos dirigem-se mais às condições e finalidades da produção. No trabalho de reflexão crítica de Lisboa (2016), que se questiona sobre o que o atrai em Três dia sem Deus, divergimos, pelo exposto, duma possível atribuição a Coelho.

\section{A Rejeição do plano de Anto}

Quatro anos após a experiência de Três dias sem Deus, pretendeu Bárbara Virgínia realizar outra longa metragem. O tema seria António Nobre, poeta preferido que frequentemente dizia em recitais (Neves, 1986, pp. 28-29). Nobre é considerado por alguma crítica como inovador na escrita, cultor do simbolismo na poesia, recorrendo a temas saudosistas e tradicionalistas. Na época, um criador ousado, note-se que a sua (curta) vida privada foi alvo de escrutínio e condenação moralista pela intimidade com outros homens.

O argumento (Vianna \& Muller, 1950) foca-se na indecisão de António (Anto) Nobre perante a escolha amorosa entre duas mulheres, uma rica e outra criada (sic) de república académica ${ }^{19}$, mostrando-se ambas, pacientes, apostadas em moderar o seu ( $\mathrm{mau}$ ) temperamento e em melhorar o aproveitamento académico. $O$ contexto invocava as práticas convencionadas para a vida estudantil (fado, noitadas, exames) e a praxe académica. Criava-se pretexto para cenas estudantis de declamação, com destaque para Nobre, e contendas a propósito de preferências literárias.

Anto seria rejeitado para financiamento pelo SNI em 1950, alegando falta de verbas, coincidindo com um controle mais opressivo à produção cinematográfica, enquadrada desde 1948 pelo Fundo de Cinema Nacional (FCN), este apoiado por um Conselho do Cinema que o governo controlava através dos representantes (Ribeiro, 2010, p. 29).

\footnotetext{
${ }^{19}$ Nome dado a residências de estudantes universitários geridas por eles ou elas.
} 
Sobre a falta de aceitação para continuar a fazer cinema em Portugal, Bárbara se publicará décadas depois: "sempre fui muito independente - por isso a censura me cortou" (itálico acrescentado pelas autoras) (Xavier, 1987, p. 18). Curiosamente, o recorte guardado contém anotações manuscritas que rodeiam a expressão realçada com pontos de interrogação. Mais do que censura, em sentido estrito, ter-se-á ressentido da acumulação de experiências de desaprovação e preterição genderizadas, tanto familiares como artísticas, que contrariavam a figura que construiu de mulher independente e autossuficiente.

Como referimos, o ideário de Bárbara Virgínia reflete dissonâncias que requerem reflexão. Contudo, não nos restam dúvidas do seu empenho numa religiosidade com o recorte conservador de uma classe social que se via como padrão moral para toda a sociedade. Tanto nos livros escritos como nos filmes dirigidos ou no projeto não realizado, aquela está presente em tipos morais exemplares, em prescrições de vida familiar. Entendemos ser hiperbólica, e talvez desejosa de polémica, a declaração sobre como ansiava por outro filme: fosse ela premiada em algum jogo de sorte faria "um filme sobre Cristo - o revolucionário, o socialista, o Homem" (Neves, 1986, pp. 28-29).

\section{Trocar Portugal pelo Brasil}

$\mathrm{Na}$ entrevista concedida aos 64 anos, Bárbara usará uma linguagem desabrida ao rememorar a saída de Portugal: "abdiquei do meu nome quando a família achou que mulher artista é prostituta. Sou apenas Bárbara Virgínia e não gostaria de falar da família, que me expulsou." (Xavier, 1987, p. 18). Contudo, já no Brasil, e depois de ter feito cerca de 600 recitais de poesia, de protagonizar as comemorações do centenário de Garrett e de ser, nessa sequência, premiada ${ }^{20}$ (Abelho, 1959, p. 52), abandona as práticas artísticas imediatamente depois do casamento para não "magoar" o marido, nas suas palavras, já que "qualquer homem que não seja do meio tem desconfiança do meio artístico" (Xavier, 1987, p. 18). A tanto se juntou a crescente adversidade do contexto brasileiro, como referiremos de seguida.

Um convite de 1954 para dirigir um filme comemorativo do IV centenário de S. Paulo terá sido recusado por Bárbara, por aconselhamento da mãe que temia aproveitamento político (Matos, 2000, pp. 74-86). As comemorações foram efetivamente usadas para celebrar também o aniversário da constituição brasileira de 1932 e o regime ditatorial de Getúlio Vargas, conhecido igualmente por Estado Novo.

Bárbara manterá uma rede de relações sociais e artísticas em São Paulo. Para tanto contribuirá substancialmente a abertura de um restaurante nessa cidade, Aqui Portugal, local de tertúlias e espetáculos onde entretinha figuras conhecidas do poder local e da cultura e estrelas como Edith Piaff, Tony de Matos, ou Amália Rodrigues (Abelho, 1959, p. 52). O estabelecimento, note-se, é nomeado a partir do filme em que atuara em 1947, Aqui, Portugal de Armando Miranda (Cunha, 2000).

No Brasil, apesar da atividade na rádio e televisão, não fará nem participará em qualquer filme. Alterara-se nesses anos a receção ao cinema português e, por arrastamento,

\footnotetext{
${ }^{20}$ A julgar pelo título do artigo a "estrela Castro Alves" teria um troféu em bronze.
} 
às suas estrelas. Heloísa Paulo (2002) refere como se frustraria, nos anos 40, a aposta de alguns empresários portugueses de ligarem o cinema português aos nacionais emigrados para o Brasil. Na década anterior a exibição de películas portuguesas, apoiada por imprensa periódica e rádio tivera algum êxito comercial. Agora a legislação brasileira protegia a produção nacional, por um lado. Por outro, conjugava-se o difícil entendimento no Brasil da pronúncia e expressões idiomáticas de Portugal com a má qualidade no som, com a superveniente decadência da produção portuguesa, o que torna esse projeto inviável, como Félix Ribeiro também comentou (Ribeiro, 1983, pp. 557-558). A oferta comercial portuguesa vai cingir-se aos musicais, de caráter regionalista, repostos sucessivamente. A partir dos anos 50 chega ao Brasil uma série de documentários portugueses com narração pomposa e temática nacionalista, glorificando as realizações do Estado Novo. Encontram alguma audiência junto de emigrados, mas enfrentam a desafeição de brasileiros habitantes de grandes centros urbanos que se ressentissem do cunho propagandístico fascista, assim como da sua desadequação estética, técnica e cultural (Paulo, 2002, pp. 83-94).

O peso grande na decisão de emigrar terá sido certamente a dificuldade em financiar-se autonomamente, a que acresceram as crescentes restrições censórias e financeiras do próprio SNI (Ribeiro, 2010). A falta de alternativas a este sistema, as barreiras de género na realização, o corte com a família do pai, tudo se conjugou para ensombrar as condições de permanência em Portugal. Mas, ironicamente no Brasil não encontrou, nos anos subsequentes, condições muito distintas para concretizar o "grande sonho" de voltar a filmar a que alude nos últimos dias da sua vida.

\section{Concluindo}

Bárbara Virgínia formou-se como mulher de classe média e como artista cultivada, no confronto com a exclusão por parte de familiares conservadores, com a auto- percebida segregação profissional de género na sua atividade e com o conservadorismo e o fechamento da vida cultural duma sociedade sob regime fascista. A apreciação de experiências adversas e a inserção em círculos sociais e profissionais artísticos, proporcionam-lhe desempenhos e narrativas identitários e um percurso variado de construção de subjetividade pública e individual. Este percurso é auto-percecionado a partir das diversas oportunidades encontradas, na formulação de Skeggs (1997), nos mercados dos recursos culturais, económicos e do casamento.

Debateu-se ambivalentemente com uma moralidade que lhe reduzia a autonomia no espaço público e a cobrava em excesso no privado. Ao diminuírem as fronteiras entre o espaço público mais publicitado e o espaço privado mais requestado publicamente, por força da sua exposição profissional, ao diminuírem as margens de manobra para artistas vigiadas e vigiados, dobraram a exigência e o escrutínio de cariz patriarcal e totalitário sobre a sua vida. Esta foi assumindo, ainda que indesejadamente, arestas mais políticas a que se não conseguia esquivar pela sua posicionalidade de autonomia e ousadia. 
A produção artística e literária analisada leva-nos a considerar que, não decorrendo de uma perspetiva feminista, a sua cinematografia demonstrou arrojo, ocasionalmente questionando e fendendo os padrões profissionais e artísticos genderizados. Ensaiou, incipientemente, o enfoque em detalhes do quotidiano e em relações sociais, segundo visão não dominante cultivada por algumas suas contemporâneas, em que a mulher é espetadora de si e não mero espetáculo (de Lauretis, 1984). Levada a interromper o percurso da realização cinematográfica, onde a custo acedeu e longamente permaneceu única, legou-nos a conjetura sobre como poderia ter sido a sua vivência, tivesse encontrado outras condições políticas e culturais.

No campo profissional, deterioração, rasura e esquecimento atingiram os seus filmes não só material como simbolicamente. Relevantes em si mesmos pelas marcas de género que veiculavam, esses apagamentos contrastam sobretudo com o apreço de que gozou a longa metragem e as atuações em palcos e rádio. Invertendo a perspetiva, a deterioração da imagem, o emudecimento do som, a incúria preservadora, ainda que não exclusivos às suas obras, realçam o que cópias perfeitas mais facilmente diluiriam: a memória foi-se construindo e erodindo a partir da des-seleção ativa da própria Bárbara mas, acima de tudo, sobre aquela outra adversa e de cunho patriarcal, ainda que passiva, que se fez e vem fazendo por parte de instituições, grupos profissionais e sociais.

\section{REFERÊNCIAS BIBLIOGRÁFICAS}

Abelho, A. (1959, 31 de janeiro). Bárbara Virgínia em bronze. Festa, p. 52.

Alcoff, L. (1988). Cultural feminism versus post-structuralism: the identy crisis in feminist theory. Signs, 13, 425 .

Alcoff, L. (1994). Cultural feminism versus Post-Structuralism: the identity crisis in feminist theory. In N. Dirks et al. (Eds.), Culture power history: a reader in contemporary social theory (pp. 96-122). Princeton, Nova Jersey: Princeton University Press.

Alcoff, L. (2005). Visible Identities: Race, Gender, and the Self. Oxford: Oxford University Press.

Bárbara Virgínia realizadora do filme "Três dias sem Deus" (1948, 31 de agosto). O Século ilustrado: revista portuguesa da actualidade mundial, 452.

Bourdieu, P. (1979). La distinction: critique sociale du jugement de goût. Paris: Les Éditions de Minuit.

Cruz, J. M.; Ferreira, A. J. \& Pina, L. de (1989). Prontuário do cinema português. Lisboa: Cinemateca Portuguesa.

Cunha, A. (2000). Cineastas portuguesas 1874-1956. Lisboa: Arquivo Municipal de Lisboa. Retirado de http:// videoteca.cm-lisboa.pt/fileadmin/VIDEOTECA/publicacoes/lista/cinema_portugues/cineastas_ portuguesas.pdf

De Lauretis, T. (1984). Alice Doesn't: Feminism, Semiotics, Cinema. Bloomington: Indiana University Press.

Esclarecimento (1946a, 30 de agosto). Diário Popular, p. 9.

Hallewell, L. (2005). O livro no Brasil: sua história. São Paulo: EdUSP. 
Lisboa, R. V. (2016). O restauro cinematográfico e a Teoria dos Cineastas: o caso de Bárbara Virgínia. In M. Penafria; E. T. Baggio; A. R. Graça \& D. C. Araujo (eds), Propostas para a teoria do cinema - Teoria dos cineastas - Vol. 2 (pp. 39-69). Covilhã: LabCom.IFP. Retirado de http://www.labcom-ifp.ubi.pt/ ficheiros/201704191500-201701_teoriacineastasii_mpenafria.pdf.

Lourenço, A. (1946, 31 de agosto). "Três dias sem Deus" de Bárbara Virgínia estreou-se no Ginásio com agrado. O Século, p.8.

Mangorrinha, Jorge. (2014). Mundo Gráfico 1940-1948 [ficha histórica]. Lisboa: Hemeroteca Digital. Retirado de http://hemerotecadigital.cm-lisboa.pt/FichasHistoricas/MundoGrafico.pdf

Marreiros, G. M. (2001). Carlos Filipe Porfírio. In Quem foi quem?: 200 Algarvios do Século XX (pp. 423-424). Lisboa: Edições Colibri. Retirado de http://republica-sba.webnode.com.pt/products/ carlos-filipe-porfirior/

Matos, H. de (2000, 23 setembro). A primeira realizadora portuguesa. Revista do Expresso, pp.74-86.

Moreira, M. T. (2013). Todos têm direito à cultura: a dinâmica cultural da cidade de Santarém (1930-1959). Tese de Doutoramento. Universidade Nova de Lisboa, Lisboa, Portugal.

Morreu a primeira realizadora portuguesa de cinema (2015, 12 de março). Jornal de Notícias. Retirado de http://www.jn.pt/cultura/interior/morreu-a-primeira-realizadora-portuguesa-de-cinema-4450111.html

Neves, J. A. da (1986, 18 de agosto). O teatro podia ser elo entre Portugal e Brasil. Diário Popular, pp. 28-29.

O filme da "simpatia" (1946, abril). Filmagem, $3 a$ série, 64, p. 5.

Paulo, H. (1994). Estado Novo e propaganda em Portugal e no Brasil: o SPN-SNI e o DIP. Lisboa: Minerva.

Paulo, H. (2002). O emigrante e o cinema: sociabilidade e nacionalismo. Locus - Revista de História, 8(2), 8394. Retirado de https://locus.ufff.emnuvens.com.br/locus/article/view/2462.

Pereira, A. C. (2013). Mulheres por detrás das câmaras: a ficção de longa-metragem, mediada por um olhar feminino. In F. Lopes \& A. C. Pereira (Eds.), Filmes Falados: Cinema em Português, V Jornadas (pp.95108). Covilhã: Livros LabCom. Retirado de http://www.livroslabcom.ubi.pt/book/101\#Abstract

Pereira, A. C. (2016). A Mulher-Cineasta: da arte pela arte a uma estética da diferenciação. Covilhã: LabCom. IFP. Retirado de http://www.labcom-ifp.ubi.pt/ficheiros/201603081045-201522_mulhercineasta_ acatarinapereira.pdf

Pimentel, I. (2011). A cada um o seu lugar: a política feminina do Estado Novo. Lisboa: Temas e Debates / Círculo de Leitores.

Pinto, R. (1951, 15 de setembro). Quando volta Bárbara Virgínia? Plateia, 12, p.12.

Ramos, J. L. (2012). Dicionário do Cinema Português: 1895-1961. Lisboa: Caminho.

Repórter Dois (1944, 30 de março). A família expulsou-a, porque ela quis ser artista! Vida Mundial, p. 11.

Ribeiro, C. P. (2010). O "Alquimista de sínteses": António Ferro e o cinema português. Dissertação de Mestrado, Universidade do Porto, Porto, Portugal. Retirado de http://repositorio-aberto.up.pt/handle/10216/55466

Ribeiro, M. F. (1983). Filmes, figuras e factos da história do cinema português 1896-1949. Lisboa: Cinemateca Portuguesa.

Sarmento, A. (1946, 15 de setembro). Três dias sem Deus da jovem realizadora Bárbara Virgínia. Gazeta do Sul, p. 5. 
Skeggs, B. (1997). Formations of class and gender: becoming respectable. Londres: Sage.

Sylvan, F. (1946, dezembro). Três dias sem Deus. Brisa, 3, pp. 22-23.

Três dias sem deus: esta noite no Ginásio, estreia de um novo filme português (1946, 30 de agosto). Diário Popular, p. 9.

Três dias sem deus: filme 100\% português dirigido por Bárbara Virgínia (1946a, 30 de agosto). [publicidade] Diário de Lisboa, p. 3.

Três dias sem deus: filme 100\% português dirigido por Bárbara Virgínia (1946b, 30 de agosto). [publicidade] Diário Popular, p. 9.

Um novo êxito do cinema português: Três dias sem Deus (1946, 31 de agosto). [publicidade] O Século, p. 3.

Vianna, J. \& Muller, A. (1950). Anto [processo apresentado ao SNI]. Arquivo da Torre do Tombo. Refas DIV 1245 (Img. Digit. a partir de microfilme) e DIV 1246 (CD), PT-TT-SNI-DGE-22-1-37_cooog a PT-TT-SNI-DGE-22-1-37_CO126.

Vieira, P. (2015). Portuguese film, 1930-1960: the staging of the New State regime. Londres: Bloomsbury.

Virgínia, B. (1972). A mulher na sociedade: manual prático e ilustrado de charme e distinção. Prior Velho: Editora Paulinas.

Virgínia, B. (1986). Poder pode... mas não deve! manual ilustrado do bem-receber, elegância, charme e etiqueta. São Paulo: Loyola.

Virgínia, B. (1992). Comportamento: dicas para o executivo ter sucesso: a etiqueta dos anos 9o. São Paulo: Loyola.

Virgínia, B. (1993). Etiquetas sem etiqueta: só para teenagers: dicas de relacionamento pessoal. São Paulo: Loyola.

Visor 42 (1946, 31 de agosto). "Três dias sem Deus" no Ginásio. Diário de Lisboa, p.5.

Xavier, L. (1987, 8 de maio). Bárbara Virgínia: memórias em São Paulo. Diário de Notícias, p.18.

Três dias sem deus (1946, 8 de março). $7 a$ Arte: revista mundial de cinema, p. 6.

\section{FiLMOGRAFIA}

Coelho, A. (1947). Aldeia dos rapazes da rua. Lisboa: Secretariado Nacional da Informação. Retirado de http:// www.cinemateca.pt/Cinemateca-Digital/Ficha.aspx?obraid=2396\&type=Video

Fonseca, R. F. da (1945). Neve em Lisboa. Lisboa: Invicta Filmes Independente.

Porfírio, C. (1945). Sonho de Amor. Lisboa: Cinelândia.

Virgínia, B. (1946). Aldeia dos rapazes: Orfanato Sta. Isabel de Albarraque. Lisboa: Invicta Filmes. Independente.

Virgínia, B. (1946). Três dias sem Deus. Lisboa: Invicta Filmes Independente. 


\section{WEBGRAFIA}

Delcamp.net (2008, outubro). Portugal vignette with error perforation religiouse 3 days without god. Retirado de http://www.delcampe.net/page/item/id,45580603,var,PORTUGAL-VIGNETTE-WITH-ERROR-

PERFORATION-RELIGIOUSE-3-DAYS-WITHOUT-GOD,language,F.html

Festival de Cannes. Sélection officielle 1946: en Compétition. Retirado de http://www.festival-cannes.fr/fr/ archives/1946/inCompetition.html

\section{Agradecimentos}

À filha de Bárbara Virgínia pela doação de livros, fotos e papéis pessoais.

A Wiliam Pianco e Ana Catarina Pereira pela partilha da gravação da entrevista que fizeram a Bárbara Virgínia, antes mesmo da sua publicação.

\section{NotAS BiográFiCAS}

Paula Sequeiros é investigadora pós-doutoral no Centro de Estudos Sociais, da Universidade de Coimbra, e investigadora associada no Instituto de Sociologia da Universidade do Porto. É licenciada em História (UP), mestra em Sociedade da Informação e do Conhecimento pela Universitat Oberta de Catalunya, doutorada em Sociologia (UP). Os seus interesses de pesquisa são a sociologia da cultura e os estudos culturais sobre a leitura e as bibliotecas públicas. As suas publicações estão disponíveis no repositório de Acesso Aberto e-LIS.

E-mail: paulasequeiros@ces.uc.pt

Centro de Estudos Sociais, Colégio de S. Jerónimo Largo D. Dinis, Apartado 3087, 3000-995 Coimbra, Portugal

Luísa Sequeira é realizadora de cinema. Estudou Jornalismo e especializou-se em realização de documentários. Durante dez anos trabalhou na RTP, produzindo vários projetos, como o Fotograma. Desde 2010 é diretora artística do Shortcutz Porto. Organiza - Super 9 Mobile Film Fest. Dirigiu os documentários Quem é Bárbara Virgínia?, Mulheres no Palco, Os Cravos e a Rocha, e os filmes experimentais, Memória, substantivo feminino e La Luna. Atualmente está a produzir o Nada a Temer, um documentário co-realizado com o artista Sama sobre a atual situação politica do Brasil, e um filme sobre As Novas Cartas Portuguesas.

E-mail: lusequeira@hotmail.com

Rua Dom António Barroso, 141, 4050-06o, Porto, Portugal

* Submetido: 01-08-2017

* Aceite: 04-11-2017 